\title{
Using Methane Hydrates (Burning Ice) As a Cleaner Source of Energy
}

\author{
${ }^{1}$ Varun Kelkar, ${ }^{2}$ ahul Mishra, ${ }^{3}$ Nitya Mohan and ${ }^{4}$ Elizabeth Joseph
}

\begin{abstract}
For decades now, petroleum and its invaluable products have been serving us. Among the multifarious fuels used to drive our cars and fly our planes, natural gas is the cleanest of all. Natural gas however, makes up only 20-25\% of global usage as a fuel. Around 75\% comprise of jet fuel, diesel oil and petrol. These petroleum derivatives are the chief culprits for the emissions of greenhouse gases into the atmosphere. Natural gas on the other hand, emits 40-50\% less carbon dioxide than these petroleum derivatives. This paper illustrates a new-found source of fuel in the form of methane hydrates. They are clathrate compounds that act as active sources of methane gas which can be exploited and used as a cleaner source of fuel. They are primarily found in the sandy sediment layer of the seabed, ranging from Alaska to Japan as also in the Andaman Islands, India. They have an ice like appearance and burn when a flame is set on them, suggestive of "burning ice". Methane hydrates are most stable in a high pressure-low temperature environment hence extraction methods are accordingly altered with special care taken to avoid methane gas leakage. This untapped and cleaner source of fossil fuels can be a turning point in the way current sources of energy are being utilized.
\end{abstract}

Keywords: Natural gas, Clathrates, Methane hydrates, Greenhouse gases.

\section{Introduction:}

The paper emphasizes on utilizing Methane Hydrates as sources of energy. Most methane hydrate deposits are major constituents of the marine geosphere, located in seafloor sediments. They are stable at that depth where pressure is high and temperature is low. Methane hydrates are distributed across the globe. The Arctic regions and the Nankai trough in Japan have successfully recovered fuel from these reserves. A map below shows the methane hydrate pockets across the world.

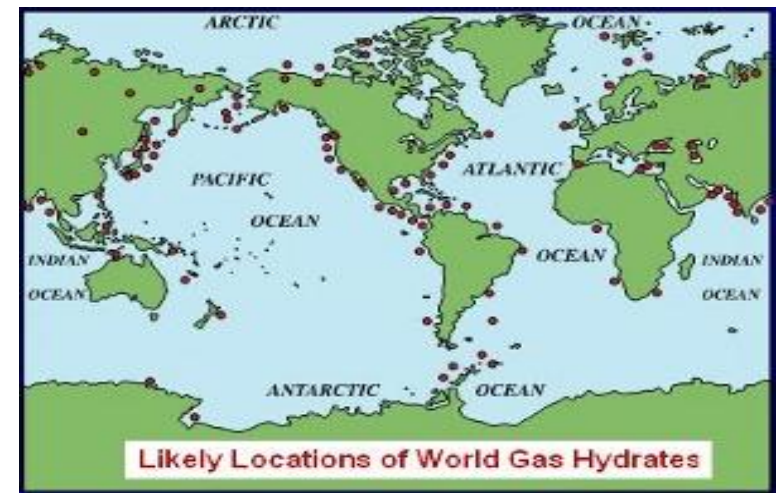

The spots marked in red denote hydrate reserves some of which have been explored and some of which are inferred to be rich in methane hydrates. Methane hydrates have long been occupying seabed and ocean floors but problems of extracting and exploiting this source of fuel thwarted its development.

So what are methane hydrates essentially?

\section{Chemistry Of Methane Hydrates}

Like all hydrocarbons, methane contains only two elements -- carbon and hydrogen. It is an example of a saturated hydrocarbon, or a molecule composed entirely of single bonds and therefore the maximum number of hydrogen atoms allowed. Methane's chemical formula is $\mathrm{CH}_{4}$. Chemists describe this shape as a tetrahedron. Methane is a colorless, odorless, combustible gas produced by bacterial decomposition of plant and animal matter. It forms in a process shared by all fossil fuels.

Methane can also form unconventionally if the sediments producing it are located about 1,640 feet (500 meters) below the ocean surface. The near-freezing temperatures and high pressure of these conditions causes the methane to become encased in ice.As soon as it reaches warmer temperatures and lower pressures, the ice 
melts away, leaving behind pure methane. Methane clathrates are generally stable at $0^{\circ} \mathrm{C}$ but at high pressures they remain stable till $18^{0} \mathrm{C}$

Gas hydrates are clathrate compounds. A clathrate is simply a structure in which water molecules under certain conditions bond to form an ice-like cage that encapsulates a gas molecule, known as a guest molecule. When that guest is a methane molecule, it is called methane hydrates. Methane forms a structural hydrate with two dodecahedral and six tetradecahedral water cages per unit cell. The average methane clathrate hydrates composition is 1 mole of methane for 5.75 moles of water. The observed density of the methane hydrates is 0.9 $\mathrm{g} / \mathrm{cc}$

\section{As a source of energy}

Generally, "conventional" methane is located beneath the earth's surface. To get to it, workers must drill through rock and sediment and tap into the methane deposits to release the gas. Then they pump it to the surface, where it's transported through pipes across the country.

The methane hydrate locations in the ocean floor trace around thousands of kilometres below.

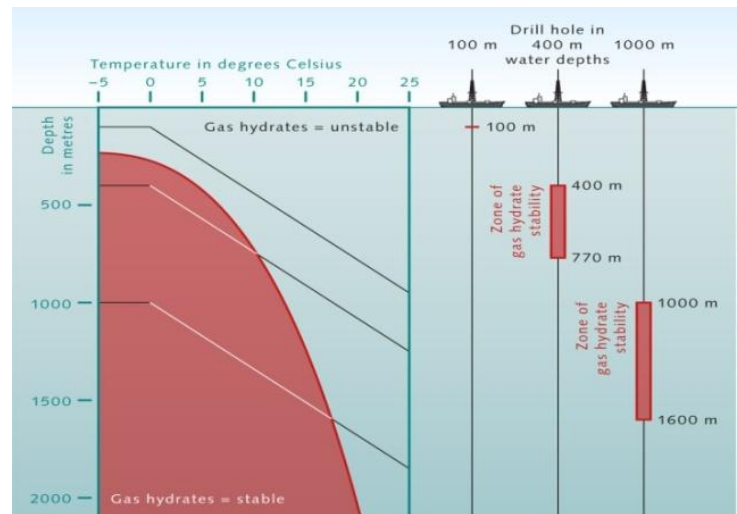

As mentioned earlier, gas hydrates are most stable in high pressure, low temperature environments like the vast depths of the ocean. Drilling through these depths requires heavy machinery as well as engineering and geological knowledge.

\section{Process Description}

Since methane hydrate is a solid substance, you can think it can be mined as coal. However, it is not efficient to mine methane hydrate because it is contained in geologic layers under a deep ocean. The production of methane hydrate means dissociating methane hydrate in the layers and collecting the resultant methane gas through wells and production systems. The operation of the "increasing temperature" or "decreasing pressure" of layers bearing methane hydrate is the actual way of the production of methane hydrate. The production method that involves increasing the temperature is called the "heating method," and another that involves decreasing the pressure is called the "depressurization method."

Methane hydrate is present in deep below the ocean bed under pressurized conditions, this can be inferred from the fact that one liter of methane clatharates contain 168 liters of methane gas itself shows that how highly compressed it is .

The Flow sheet below shows the extraction of natural gas to its purification to be ready for usage.

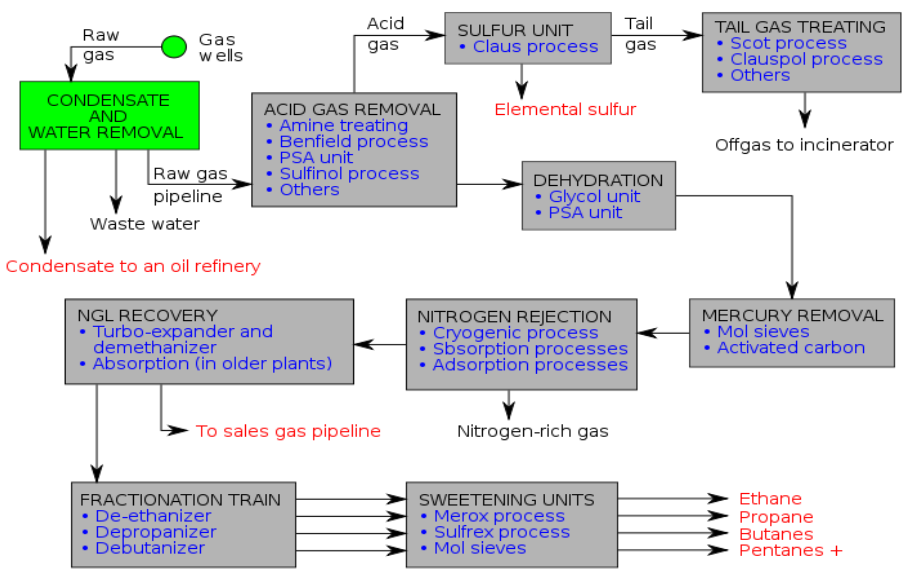


1. When natural gas is extracted from the well located offshore middle of the ocean it has several components which are not desirable for its day to day use as a combustion fuel. Some of them include acid gas, water, mercury, nitrogen etc.

2. First process which the natural gas undergoes is the water removal and it also gives rise to condensate. Both are separated at the start of the process.

3. Next process is the acid gas removal process. It includes amine treating, Benfield process, pressure swing adsorption unit, sulfinol process and other processes. Benfield process removes hydrogen sulphide and carbon dioxide from the crude gas. PSA unit adsorbs the unwanted gases. Sulfinol process also removes sulphur gases and all these processes in reduce the energy consumption by eliminating the waste gases. The acid gases removed are further sent for processes to recover the elemental forms of the components

4. Later stage is dehydration unit where the water is removed in a adsorber unit (PSA unit)

5. Next stage is mercury removal which is a poisonous compound and hazardous to human health. Molecular sieves and activated carbon help reduce the mercury level content by a considerable level.

6. Next stage is nitrogen removal where cryogenic process and adsorption is used to remove nitrogen. Adsorption is not used because it incurs loss of butane and other heavy hydrocarbons. One of these processes may be used. This nitrogen rich gas is recovered and used for other nitrogen involving processes.

7. The next step is to recover the natural gas liquids (NGL) for which most large, modern gas processing plants use another cryogenic low temperature distillation process involving expansion of the gas through a turbo-expander followed by distillation in a demethanizingfractionating column. Some gas processing plants use lean oil absorption process rather than the cryogenic turbo-expander process.

8. The residue gas from the NGL recovery section is the final, purified sales gas which is pipelined to the end-user markets.

9. The recovered NGL stream is sometimes processed through a fractionation train consisting of three distillation towers in series: a deethanizer, a depropanizer and a debutanizer. The overhead product from the deethanizer is ethane and the bottoms are fed to the depropanizer. The overhead product from the depropanizer is propane and the bottoms are fed to the debutanizer. The overhead product from the debutanizer is a mixture of normal and iso-butane, and the bottom product is a $\mathrm{C}_{5}+$ mixture. The recovered streams of propane, butanes and $\mathrm{C}_{5}+$ may be "sweetened" in a Merox process unit to convert undesirable mercaptansinto disulfides and, along with the recovered ethane, are the final NGL byproducts from the gas processing plant. Currently, most cryogenic plants do not include fractionation for economic reasons, and the NGL stream is instead transported as a mixed product to standalone fractionation complexes located near refineries or chemical plants that use the components for feedstock. In case laying pipeline is not possible for geographical reason,or the distance between source and consumer exceed $3000 \mathrm{~km}$, natural gas is then transported by ship as LNG(liquefied natural gas) and again converted into its gaseous state in the vicinity of the consumer.

\section{Scope For Hydrate Extraction}

There is a huge reserve of Methane Hydrate all over the world estimated at around 8 billion trillion cu. meters as compared to 440 trillion cu. meters of natural gas reserves. Extraction of these reserves is not yet started in a full swing but Japan has started its extraction way earlier than others. Various problems were encountered in its extraction.

Firstly it's situated deep under the sea bed stabilizing the ocean floor. Extraction carried out will ultimately result in destabilizing the tectonic plates and may trigger tsunamis and earthquakes, submarine slumping, landslides or subsidence that can damage production equipment and pipelines. Hence extraction under the guidance of geological experts extraction can be proceeded. Another problem is the leakage of the methane gas while its extraction and transportation. Methane is a green house gas and its danger levels are 20 times more than that of carbon dioxide. Thus a problem of global warming standsTheprobable solutions to these problems are being worked out through continuous research and feasibility analyses.

\section{Cost}

The economic gas production from gas hydrate reserve is difficult to analyze. Reports state that the price of gas would have reach to \$7.50(Canadian dollars) per Mcf production from permafrost associated gas hydrates overlying producible free gas to be economically viable. If there is no underlying free gas that can be produced during the life of the well, then the prices would have reach upto $12 \$$ (Canadian dollars). 


\section{Progress In Japan}

On March 12, 2013, JOGMEC researchers announced that they had successfully extracted natural gas from frozen methane hydrate. In order to extract the gas, specialized equipment was used to drill into and depressurize the hydrate deposits, causing the methane to separate from the ice. The gas was then collected and piped to surface where it was ignited to prove its presence. It was the world's first offshore experiment producing gas from methane hydrate. Previously, gas had been extracted from onshore deposits, but never from offshore deposits which are much more common. This hydrate extraction was done in NANKAI trough $300 \mathrm{~m}$ deep under the sea. Japan finally had their own resource. Now, since the extraction was possible. The next step for Japan was to make the resource economically viable and make the extraction process more efficient. Japan estimates that there are at least 1.1 trillion cubic meters of methane trapped in the NANKAI Trough, enough to meet the country's needs for more than ten years. The first onshore extraction was carried out in 2002 at the Mallik site in the Mackanzie delta in Canada.

\section{Conclusion}

Methane hydrates as seen are clathrate compounds and active sources of methane.

This source can buy us some more time for our discoveries of renewable sources that can be implemented on a large scale. It will certainly prove to be a better bet over petroleum, with proper extraction and distribution and surely be environmentally friendlier.

If efficient and cost-effective drilling and procuring methods are set in place, owing to progress in research and development, this could be deemed as a potential fuel of the future.

\section{Reference}

[1]. Japan oil, gas and metals national corporation; promoting the development of methane hydrates, accessed on $20^{\text {th }}$ February, 2014 .

[2]. How stuff works; how frozen fuel works, accessed on 20th February, 2014

[3]. 'MH21 research consortium', accessed on $4^{\text {th }}$ march, 2014

[4]. Wiley online library, journal of geophysical research, accessed on $20^{\text {th }}$ February, 2014

[5]. Carolyn Ruppel; "methane hydrate and the future of natural gas" supplementary paper 4.

[6]. Micheal D. Max ; "Coastal Systems and continental margins, natural gas hydratein oceanic and permafrost environment", Kulwer academic publishers, Netherland.

[7]. Greening of oil, Methane a future clean energy source, accessed on $5^{\text {th }}$ march, 2014. 